\title{
Analisis Kecerdasan Ekologis Mahasiswa Calon Guru Biologi Melalui Model Pembelajaran Berbasis Masalah dengan Bantuan Diagram Vee
}

\author{
Diki M. Chaidir ${ }^{1,2}$ Sri Redjeki ${ }^{2}$ Anna F. Hindriani ${ }^{2}$ Purwati K. Suprapto ${ }^{1}$ Liah Badriah $^{1}$ \\ 1Jurusan Pendidikan Biologi FKIP Universitas Siliwangi \\ 2Program Studi Pendidikan Biologi, Sekolah Pascasarjana, Universitas Kuningan \\ 1Jalan Siliwangi No.24, Kahuripan, Tawang, Tasikmalaya, Jawa Barat 46115 \\ 2 Jalan Pramuka No. 67. Purwawinangun, Kuningan, Jawa Barat 45512 \\ Email : dikimc@unsil.ac.id
}

\begin{abstract}
Abstrak
Latar belakang penelitian ini adalah kegiatan pembelajaran lebih terfokus kepada pemahaman teori saja serta berpusat kepada dosen (teacher centered oriented), sehingga mengakibatkan masih rendahnya kemampuan berpikir tingkat tinggi serta masih banyak yang membuang sampah sembarangan yang menandakan masih kurangnya kecerdasan ekologis. Penelitian ini bertujuan untuk mengetahui pengaruh model pembelajaran berbasis masalah dengan bantuan diagram Vee terhadap kecerdasan ekologis mahasiswa calon guru biologi pada mata kuliah Ekologi Tumbuhan. Pengukuran kecerdasan ekologis menggunakan tes pilihan ganda dengan jumlah lima pilihan yang disesuaikan dengan indikator kecerdasan ekologis. Dari hasil penelitian dapat disimpulkan bahwa implementasi model pembelajaran berbasis masalah dengan bantuan diagram Vee pada kelas eksperimen memiliki perbedaan hasil kecerdasan ekologis dibandingkan mahasiswa calon guru biologi dengan kelas kontrol yang proses pembelajarannya menggunakan model pembelajaran langsung, model pembelajaran berbasis masalah dengan bantuan diagram Vee mempunyai rata-rata $\mathrm{N}$-Gain yang lebih baik dibandingkan dengan model pembelajaran konvensional terhadap kecerdasan ekologis mahasiswa calon guru biologi. Persentase peningkatan kecerdasan ekologis tertinggi pada kelas eksperimen terdapat pada indikator pengetahuan tentang prediksi permasalahan lingkungan di masa yang akan datang.
\end{abstract}

Kata Kunci-. Calon Guru Biologi, Diagram Vee, Kecerdasan Ekologis, Pembelajaran Berbasis Masalah

\begin{abstract}
The background of this research is the learning activities are more focused on theoretical understanding only and teacher centered oriented, resulting in low level of thinking ability and many that throw garbage indiscriminately indicating the lack of ecological intelligence. This study aims to determine the effect of problem-based learning model with the help of Vee diagram to the ecological intelligence of biology prospective teacher in the course of Plant Ecology. The measurement of ecological intelligence uses multiple choice tests of a total five options that are adjust to the ecological intelligence indicator. The research result it can be concluded that the implementation of problem-based learning model with the help of Vee diagram in the experimental class has the difference of ecological intelligence result compared to the biology prospective teacher with the control class whose learning process is using the direct learning model, the problem-based learning model with the help of Vee diagram has the average, average of $\mathrm{N}$-Gains compared to direct instruction learning of ecological intelligence of biology prospective teacher. The highest percentage increase in ecological intelligence in the experimental class is in the knowledge indicator of predicted future environmental problems.
\end{abstract}

Keywords: Biology Prospective Teacher, Ecological Intelligence, Problem Based Learning, Vee Diagram 


\section{PENDAHULUAN}

Salah satu permasalahan yang harus dihadapi dalam pendidikan di Indonesia adalah lulusan dari sekolah atau perguruan tinggi yang belum siap memasuki dunia kerja, hal tersebut dikarenakan masih minimnya kompetensi yang dimiliki oleh lulusan tersebut. Kegiatan pembelajaran yang hanya terpaku kepada pemahaman teori saja menjadi salah satu penyebab banyak lulusan yang kurang inovatif dan kreatif. Hal tersebut mengakibatkan banyak kalangan yang berpendapat bahwa kualitas SDM yang rendah tersebut mengakibatkan banyak persoalan yang harus dihadapi oleh bangsa Indonesia (Kunandar, 2007:1).

Selain itu pentingnya mahasiswa calon guru biologi memiliki kecerdasan ekologis yaitu dapat membuat individu menerapkan apa yang dipelajari segala sesuatu sebagai akibat dari aktivitas manusia terhadap ekosistem, sehingga dapat mengurangi kerusakan lingkungan hidup dan mencegah kerusakan dalam bumi ini (Goleman, 2010, dalam Muhaimin 2015:86).

Sebagai mahasiswa calon guru biologi tentu saja mempunyai tuntutan menguasai konten biologi itu sendiri dan komptensi pedagogik, sebagai bekal dalam pembelajaran biologi yang dilakukan di sekolah nanti. Mahasiswa juga perlu dilatih dalam mencari solusi terkait fenomena yang terjadi di masyarakat saat ini. Hal tersebut tentu saja tidak bisa dilakukan hanya dengan menggunakan model pembelajaran konvensional yang lebih berpusat kepada dosen.

Salah satu model pembelajaran yang sering digunakan untuk menunjang pembelajaran yang lebih berpusat kepada siswa/mahasiswa dan memberdayakannya adalah model Pembelajaran Berbasis Masalah. Model pembelajaran ini memberikan pengalaman lebih kepada mahasiswa juga membantu para mahasiswa dalam membangun pengetahuannya. Peran dosen di sini hanya memfasilitasi berlangsungnya kegiatan pembelajaran. Model Pembelajaran Berbasis Masalah ini mempunyai ciri khas yaitu pembelajaran dimulai dengan pemberian masalah yang memiliki konteks dunia nyata. Mahasiswa secara aktif merumuskan dan mengidentifikasi kesenjangan pengetahuan mereka terkait permasalahan, mem- pelajari dan mencari sendiri untuk memecahkan masalah masalah hingga mendapatkan kesimpulan yang dibimbing oleh dosen. Smith (2005 dalam Amir. Taufiq 2015:27) yang khusus meneliti berbagai dimensi manfaat dari Pembelajaran Berbasis Masalah menemukan bahwa pemelajar akan meningkat kecakapan pemecahan masalahnya, lebih mudah mengingat, meningkat pemahamannya, meningkat pengetahuannya yang relevan dengan dunia praktik, mendorong mereka penuh pemikiran, membangun kemampuan kepemimpinan dan kerja sama, kecakapan belajar, dan memotivasi pemelajar.

Model Pembelajaran Berbasis Masalah akan lebih sesuai apabila ditambahkan Diagram Vee dalam proses pembelajarannya, karena dengan Diagram Vee dapat mengajak mahasiswa untuk berpikir ilmiah dan mengajak mahasiswa untuk menemukan suatu konsep. Hal tersebut tentu saja sejalan dengan langkah-langkah yang ada pada model Pembelajaran Berbasis Masalah. Maka dari itu Diagram Vee akan sangat membantu dalam pelaksanaan pembelajaran di kelas yang menggunakan model Pembelajaran Berbasis Masalah.

Sintaks yang ada di dalam model pembelajaran problem based learning dapat membuat mahasiswa terbiasa dalam mencari permasalahan yang terjadi pada masa kini, serta membiasakan mahasiswa dalam mencari solusi ke arah yang lebih baik agar menghindari terjadinya kerusakan lingkungan yang ada, sedangkan dengan diagram Vee mahasiswa akan terbiasa menggabungkan suatu teori dengan metodologi hingga mendapatkan kesimpulan dan klaim nilai yang memberikan manfaat dari apa yang dipelajarinya. Oleh karena itu dengan kecerdasan ekologis yang menunjang diharapkan para calon guru biologi ini dapat menerapkan pembelajaran yang lebih baik lagi dan mengurangi berbagai permasalahan lingkungan yang ada di masa yang akan datang.

Menurut Hamzah (2013 dalam Muhaimin, 2015:88) kepedulian terhadap lingkungan hidup merupakan wujud sikap mental individu yang direfleksikan dalam perilakunya. Sikap mental terhadap lingkungan bukan talenta atau naluri bawaan, tetapi merupakan hasil dari suatu proses 
pendidikan. Sehingga kecerdasan ekologis yang dimiliki oleh seorang calon guru biologi merupakan salah satu hal yang penting dalam menanamkan sikap peduli lingkungan terhadap peserta didiknya kelak.

\section{METODE PENELITIAN}

Metode Penelitian yang digunakan dalam penelitian ini adalah metode kuasi eksperimen. Desain penelitian dalam penelitian ini adalah Nonequivalent control group design. Dimana pengambilan sampel tidak dilakukan secaa acak serta kedua kelas sama-sama dilakukan pre-test dan post-test hanya saja pada kelas eksperimen yang diberikan perlakuan.

Populasi dalam penelitian ini adalah mahasiswa calon guru biologi semester 6 yang mengambil mata kuliah Ekologi Tumbuhan di Jurusan Pendidikan Biologi FKIP Universitas Siliwangi Kota Tasikmalaya. Pengambilan sampel dilakukan secara Purposive Sampling sebanyak dua kelas. Dasar pertimbangan dilakukan berdasarkan rekomendasi dari dosen pengampu mata kuliah karena kedua kelas yang digunakan memiliki keaktifan yang sama.

\section{HASIL DAN PEMBAHASAN}

Berdasarkan hasil analisis penelitian uji perbedaan dua sampel bebas (Uji Mann-Whitney) diperoleh kesimpulan bahwa zhitung lebih besar dari ztabel (286>-3,724), maka dapat disimpulkan terdapat perbedaan rata-rata $\mathrm{N}$-gain antara mahasiswa yang proses pembelajarannya menggunakan model pembelajaran berbasis masalah dengan bantuan diagram Vee dengan mahasiswa yang menggunakan model pembelajaran konvensional.

Kecerdasan ekologis mahasiswa yang proses pembelajarannya menggunakan model pembelajaran berbasis masalah dengan bantuan diagram Vee memiliki nilai rata-rata $\mathrm{N}$-gain yang lebih baik dibandingkan dengan mahasiswa yang proses pembelajarannya menggunakan model pembelajaran konvensional. Hal tersebut karena proses pembelajaran dengan menggunakan model pembelajaran berbasis masalah dengan bantuan diagram Vee menuntut mahasiswa terampil dalam memecahkan masalah baik masalah yang berkaitan dengan akademik maupun masalah yang ada dalam kehidupan sehari-hari. Mahasiswa diharapkan menjadi solusi dari beragam masalah ekologi yang mungkin dihadapai lingkungan dan masyarakatnya di masa yang akan datang.

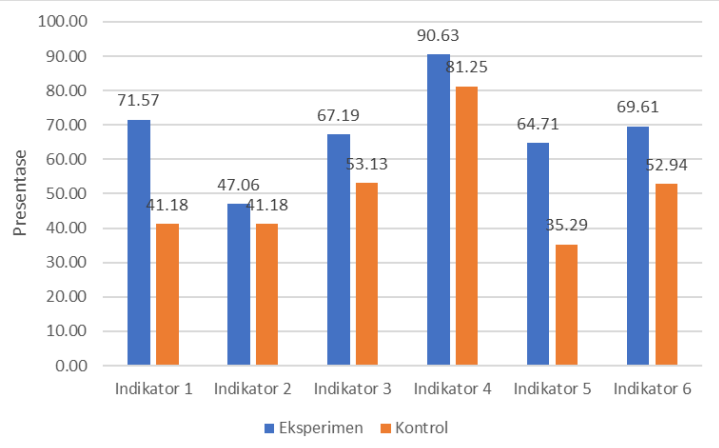

Gambar 1. Persentase Jumlah Mahasiswa Calon Guru Biologi Terkait Kecerdasan Ekologis Berdasarkan Indikator

Berdasarkan gambar 1. pencapaian indikator pada kelas eksperimen terlihat lebih tinggi di setiap indikator dibandingkan dengan kelas kontrol. Pada kelas eksperimen indikator 1 pengetahuan tentang masalah-masalah lingkungan dalam kehidupan sehari-hari $(71,57 \%)$ sedangkan kelas kontrol $(41,18 \%)$, pada kelas eksperimen indikator 2 pengetahuan tentang penyebab permasalahan lingkungan $(47,06 \%)$ sedangkan pada kelas kontrol $(41,18 \%)$, pada kelas eksperimen indikator 3 pengetahuan tentang dampak permasalahan lingkungan $(67,19 \%)$ sedangkan kelas kontrol $(53,13 \%)$, pada kelas eksperimen indikator 4 pengetahuan tentang prediksi permasalahan lingkungan di masa yang akan datang $(90,63 \%)$ sedangkan kelas kontrol $(81,25 \%)$, pada kelas eksperimen indikator 5 pengetahuan tentang solusi atau alternatif untuk menyelesaikan permasalahan lingkungan $(64,71 \%)$ sedangkan kelas kontrol $(35,29 \%)$ dan pada indikator 6 pemahaman tentang ketergantungan manusia dan lingkungan serta saling ketergantuan individu, kelompok, komunitas dan bangsa dalam pengelolaan lingkungan hidup baik dalam konteks lokal maupun global $(69,61 \%)$ sedangkan kelas kontrol $(52,94 \%)$.

Berdasarkan gambar 1 juga tampak bahwa indikator pencapaian yang paling banyak dapat dijawab adalah indikator ke $4(90,63 \%)$ pada ke- 
las eksperimen hal yang sama pada kelas kontrol adalah indikator $4(81,25 \%)$ yaitu terkait pengetahuan tentang prediksi permasalahan lingkungan di masa yang akan datang. Hal tersebut dikarenakan pembelajaran berbasis masalah dengan menggunakan bantuan diagram Vee yang dilaksanakan menggunakan berbagai sumber yang representatif yang memberikan informasi tentang pola-pola permasalahan lingkungan pada dunia nyata membuat mahasiswa dapat berpikir reflektif tentang prediksi mengenai permasalahan lingkungan yang di masa yang akan datang. Sejalan dengan pendapat Amir (2015:28) dimana salah satu manfaat dari model pembelajaran berbasis masalah mendorong pemelajar untuk mempertanyakan, kritis dan reflektif, sehingga nalar pemelajar dilatih, dan kemampuan berpikir ditingkatkan.

Persentase jumlah mahasiswa kecerdasan ekologis berdasarkan indikator yang paling kecil pada kelas eksperimen terdapat pada indikator 2 yaitu pengetahuan tentang penyebab permasalahan lingkungan, hal tersebut dikarenakan dalam mengajukan pertanyaan kepada mahasiswa terkait fenomena permasalahan perubahan iklim dan global warming, dosen tidak memberikan pertanyaan yang bersifat epistomologi, sehingga mahasiswa cenderung terburu-buru dalam menemukan suatu permasalahan lingkungan tanpa mengetahui dalam melakukan investigasi lebih mendalam analisis penyebab permasalahan lingkungan.

Peningkatan kecerdasan ekologis kelas eksperimen diduga oleh beberapa hal yang terdapat pada proses pembelajaran dengan menggunakan model pembelajaran berbasis masalah dengan bantuan diagram Vee diantaranya, proses pembelajaran PBL yang diawali dengan orientasi mahasiswa pada masalah terutama masalah yang berkaitan dengan perubahan iklim dan pemanasan global yang merupakan masalah dalam lingkungan hidup sehingga memberikan pengetahuan kepada mahasiswa tentang banyak dan kompleksnya permasalahan lingkungan hidup yang ada di masyarakat, sekaligus mengasah kepekaan mahasiswa dengan kepedulian terhadap lingkungan. Dalam proses pemecahan masalah yang dilakukan secara menyeluruh mahasiswa dapat menentukan, menganalisis dan mengevaluasi kelebihan serta kekurangan terhadap solusi yang ditawarkan sehingga solusi yang ditawarkan dapat memberikan pengetahuan yang lebih baik terhadap lingkungan di masa yang akan datang.

Peningkatan kecerdasan ekologis juga terlihat pada perubahan sikap mahasiswa yang sudah tidak lagi membuang sampah sembarangan baik di dalam kelas maupun luar kelas. Penggunaan plastik yang biasa digunakan untuk membawa buku tambahan atau kebutuhan lain yang tidak dimasukan ke dalam tas diganti dengan goody bagi yang bisa digunakan berulang kali. Hal tersebut sejalan dengan pendapat Capra (dalam Keraf, 2014:127) orang yang sudah mencapai taraf ecoliteracy adalah orang yang sudah sangat menyadari betapa pentingnya lingkungan hidup, pentingnya menjaga dan merawat bumi, ekosistem, alam sebagai tempat tinggal dan berkembangnya kehidupan.

Kecerdasan ekologis perlu terus ditingkatkan dan dikembangkan agar pengetahuan, sikap dan keterampilan mahasiswa calon guru biologi dapat mengubah sudut pandang akan pentingnya lingkungan dan menjaga pelestariannya. Hal tersebut dilakukan sebagai calon guru biologi yang diharapkan mempunyai bekal dalam kecerdasan ekologis tidak hanya untuk diri sendiri akan tetapi agar dapat mendidik peserta didiknya kelak di masa yang akan datang. Pentingnya memiliki kecerdasan ekologis pada akhirnya dapat menumbuhkan kepedulian, komitmen untuk melindungi, memperbaiki serta memanfaatkan lingkungan hidup lebih bijaksana.

\section{KESIMPULAN}

Berdasarkan hasil penelitian yang telah dilakukan, dapat disimpulkan bahwa kecerdasan ekologis mahasiswa calon guru biologi mengalami peningkatan dengan menggunakan model pembelajaran PBL dengan bantuan diagram Vee terutama terkait dengan indikator pengetahuan tentang prediksi permasalahan lingkungan di masa yang akan datang. Selain itu perubahan sikap mahasiswa calon guru terhadap lingkungan sekitar berubah, mahasiswa semakin menyadari perannya dalam kehidupan di dalam kedudukan ekologis yang menandakan kecerdasan ekologis 
yang dimiliki.

\section{DAFTAR PUSTAKA}

Amir, Taufiq. 2015. Inovasi Pendidikan Melalui Problem Based Learning. Jakarta: Prenadamedia.

Daniel Goleman. 2009. Ecological Intelligence: How Knowing the Hidden Impacts of What We Buy Can Change Everything. New York: Broadway Books,

Keraf, Sonny A. 2014. Filsafat Lingkungan Hidup: Alam sebagai Sebuah Sistem Kehidupan (Bersama Fritjof Capra). Yogyakartya: Kanisius.

Kunandar. 2007. Guru Profesional. Implementasi Kurikulum Tingkat Satuan Pendidikan (KTSP) dan Sukses dalam Sertifikasi Guru. Jakarta : PT Raja Grafindo Persada.

McBride, B. B., C. A. Brewer, A. R. Berkowitz, andW. T. Borrie. 2013. Environmental literacy, ecological literacy, ecoliteracy: What do we mean and how did we get here? Ecosphere 4(5):67. http://dx.doi.org/10.1890/ES13-00075.1

Muhaimin. 2015. Membangun Kecerdasan Ekologis. Bandung: Alfabeta.

Utina, Ramli. 2012. Kecerdasan Ekologis Dalam Kearifan Lokal Masyarakat Bajo Desa Torosiaje Provinsi Gorontalo. Mataram. Prosiding Konferensi Dan Seminar Nasional Pusat Studi Lingkungan Hidup Indonesia Ke 21. ISBN; 978-602-18848-0-5 (Halaman: $14-20$ ).

Penulisan buku dengan editor disertai (Ed.) untuk satu editor dan (Eds.) untuk lebih dari satu editor. Contohnya:

Maher, B. A. (Ed.). (1964-1972). Progress in experimental personality research (6 vols.). New York: Academic Press.

Duncombe, J.U. (1959). Infrared navigationPart I: An assessment of feasibility (Periodical style). IEEE Trans. Electron Devices, 11(5), 34-39.

Chen, S., Mulgrew, B., and Grant, P.M. (1989). A clustering technique for digital communications channel equalization using radial basis function networks. IEEE Trans. Neural Networks, 4, 570-578.
Lucky, R.W. (1965). "Automatic equalization for digital communication," Bell Syst. Tech. J., 44(4), 547-588.

Fang, Q., Zhao, F., \& Guibas, L. (2003). Lightweight sensing and communication protocols for target enumeration and aggregation. In M. Gerla, A. Ephremides, \& M. Srivastava (Eds.), MobiHoc '03 fourth ACM symposium on mobile ad hoc networking and computing (pp. 165-176). New York, NY: ACM Press.

Banks, I. (n.d.). The NHS Direct healthcare guide. Retrieved from http://www.healthcareguide.nhsdirect.nhs.uk

Alexander, J., \& Tate, M. A. (2001). Evaluating web resources. Retrieved from Widener University, Wolfgram Memorial Library website:

http://www2.widener.edu/Wolfgram-

Memorial

Library/webevaluation/webeval.htm

Bibliographic references Harvard format APA style. (2011). Retrieved from University of Portsmouth website: http://www.port.ac.uk/library/guides/filetodo wnload,137568,en.pdf 